\title{
Yabancı Uyruklu Öğrencilerin Türkçe Öğrenme Sürecinde Akran Öğretiminin Etkisi: Deneysel Bir Çalışma
}

DOI: $10.26466 /$ opus.730411

*

\author{
Mevlüt Kara* - Sevilay Şahin** - Seyfettin Kapat *** \\ *Dr. Öğr. Üyesi, Gaziantep Üniversitesi, Nizip Eğitim Fakültesi, Gaziantep/Türkiye \\ E-Posta: mevlutkara85@gmail.com \\ ORCID: 0000-0002-6381-5288 \\ **Prof. Dr., Gaziantep Üniversitesi, Gaziantep Eğitim Fakültesi, Gaziantep/Türkiye \\ E-Posta: ssahin@gantep.edu.tr \\ ORCID: $\quad$ 0000-0002-7140-821X \\ ***Öğretmen, Milli Eğitim Bakanlığı, Gaziantep/Türkiye \\ E-Posta: seyfettinkapat@gmail.com \\ ORCID: $\underline{0000-0003-2211-3025}$
}

Öz

Yabancı uyruklu öğrencilerin göç ettikleri ülkelerde yaşadıkları önemli sorunların başında dil problemi gelmektedir. Bu öğrencilerin özellikle dili konuşma ve anlama becerilerinde sorun yaşamalar bu soruna yönelik çözümleri önemli kılmaktadır. Akran öğretimi yönteminin de bu açıdan önemli çözüm seçeneği oluşturabileceği düşünülmektedir. Bu araştırmanın amacı, yabancı uyruklu (Suriyeli) öğrencilerin Türkçe öğrenimi sürecinde akran öğretiminin etkisini incelemektir. Bu araştırmada, yar deneysel araştırma türlerinden biri olan ön test/son test eşitlenmemiş kontrol gruplu model kullanılmıştır. Araştırmanın örneklemini Gaziantep'in Nizip ilçesinde yer alan bir ilkokuldaki 92 yabancı uyruklu (Suriyeli) öğrenci oluşturmaktadır. Bu öğrencilerden 50'si deney grubunda, 42'si ise kontrol grubunda yer almaktadır. Deney grubunda bulunan öğrenciler, araştırmacılar tarafindan hazırlanan ve 5 hafta süren akran öğretimi uygulamasına tabi tutulmuştur. Verilerin analizi sürecinde, deney ve kontrol grupları arasında karşılaştırma yapmak için t-testi kullanılmıştır. Araştırma sonucunda, yabancı uyruklu öğrencilerin Türkçe öğrenme sürecinde akran öğretiminin olumlu etkisi olduğunu gösteren bulgular elde edilmiştir. Araştırmanın bulguları ve sonuçları dikkate alınarak önerilerde bulunulmuştur.

Anahtar Kelimeler: Akran öğretimi, Suriyeli öğrenciler, Türkçe eğitimi, Yabancı Uyruklu Öğrenciler 


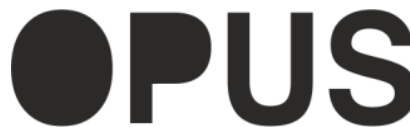

Uluslararası Toplum Araştırmaları Dergisi International Journal of Society Researches
E-ISSN : 2528-9535

YIl Year: 10

Cilt Volume: 16

Sayı Issue :Eğitim ve Toplum Özel Sayısı

Aralık December 2020

Makalenin Geliș Tarihi Received Date: 01/05/2020

Makalenin Kabul Tarihi Accepted Date: 29/12/2020

\title{
The Effect of Peer Teaching on the Turkish Learning Process of Foreign Students: An Experimental Study
}

\begin{abstract}
Language is one of the most significant problems experienced by foreign students in the countries they migrated to. These students' having problems especially in speaking and understanding the local language makes proposing a solution important. In this respect, it is believed that peer teaching method can be a useful option. The aim of this study was to examine the effect of peer teaching on the Turkish learning process of foreign students (Syrian). Nonrandomized control group pre-test/post-test model, one of the semi-experimental research designs, was used. The sample of the study consisted of 92 foreign students (Syrian) in a primary school in Nizip district of Gaziantep. Among the participating group, 50 of them were in the experimental and 42 were in the control groups. Students in the experimental group were subjected to peer teaching practices prepared by researchers and lasting 5 weeks. In the process of analyzing the data, the t-test was used to compare between the experimental and control groups. As a result of the research, findings were obtained showing that peer teaching has a positive effect on the Turkish learning process of foreign students. Some suggestions were offered considering the findings and results of the present study.
\end{abstract}

Keywords: Peer teaching, Syrian students, Turkish education, Foreign students 


\section{Giriş}

İnsanlık tarihi kadar eskiye dayanan göç olgusu tarih boyunca farklı nedenlerle gerçekleşmiştir. Eski çağlarda yiyecek ve otlak bulma gibi ihtiyaçlar nedeniyle gerçekleştirilen göç, sanayi devrimi ve küresel savaşlar ile birlikte insanların yaşamlarını devam ettirme, eğitim ve ekonomik ihtiyaçlarını giderme gibi nedenlerle gerçekleştirilmektedir. Göç; bireylerin veya toplulukların ekonomik, toplumsal, siyasi sebeplerle bir ülkeden başka bir ülkeye, bir yerleşim yerinden başka bir yerleşim yerine gitme işi olarak tanımlanmıştır (Türk Dil Kurumu [TDK], 2019). Göç, oluşumunda meydana gelen faktörler dikkate alındığında serbest göç ve zorunlu göç olmak üzere iki başlıkta toplanabilir. Bireylerin, bulundukları bölgeden daha iyi şartlar elde etmek amacıyla ayrılarak, ekonomik, sosyal ve kültürel alanda daha gelişmiş bir yere tamamen kendi özgür iradeleriyle gitme istekleri serbest göç olarak tanımlanmaktadır (Ergün, 2017). Zorunlu göç ise; savaşlar, insan hakları ihlalleri, siyasi baskılar, doğal afetler, açlık, kıtlık ve salgın hastalıklar gibi etmenlerden dolayı kişilerin yasal ya da yasal olmayan yollarla yaşadıkları ülkeyi terk etmelerine denir (Somuncu, 2006). Türkiye coğrafi konumundan ve bölgesinde yaşanan krizler karşısında mağdur insanlara kucak açan politikalar benimsemesinden dolayı göç hareketliliğinden en çok etkilenen ülkelerin başında bulunmaktadır (Göç İdaresi Genel Müdürlüğü [GİGM], 2017).

Suriye'de 15 Mart 2011 tarihinde gösterilerle başlayan ve Nisan 2011 tarihinde ülke geneline yayılan muhalif hareket, kısa bir süre içerisinde iç savaşa dönüşmüştür. Ülkelerindeki siyasi iktidarsızlık, yaşam koşulları ve baskıcı rejimden kaçıp zorunlu olarak göç eden mültecileri - 11 Eylül 2001'den sonraki yüksek güvenlikli politikalar nedeniyle (Danış, 2004)- Batı ülkeleri kabul etmemiştir. Suriye'de yaşayan sivil halk Ürdün, Mısır, Lübnan ve Türkiye gibi en yakınında bulunan komşu ülkelere zorunlu olarak göç etmek durumunda kalmıştır. Türkiye, sığınma talebinde bulunan Suriyeli mültecilere yönelik 'Açık Kapı' politikası izlemiş ve ayrım gözetmeksizin tüm mültecileri kabul etmiştir.

“Geçici Koruma Statüsü" ile Türkiye'ye kabul edilen Suriyeliler ilk etapta çeşitli illerde (Gaziantep, Kilis, Hatay, Şanlıurfa ve Adıyaman gibi) kurulan geçici barınma merkezlerine yerleştirilmiştir. Küçük gruplar halinde başlayan göç dalgası zamanla kitlesel bir göç halini almıştır. Türkiye'ye göç 
eden Suriyeli mülteci sayısının çok fazla artmasından dolayı mülteciler geçici barınma merkezlerine yerleştirilememiş ve ülkenin çeşitli illerine dağılmıştır. Geçici barınma merkezlerinde ve şehir merkezlerinde yaşamaya başlayan mülteciler Türkiye için toplumsal, sosyal, ekonomik, kültürel ve eğitimle ilgili alanlarda çeşitli sorunları gündeme getirmiştir. Bu çerçevede Türkiye'ye göç eden Suriyeli mültecilerin önemli bir bölümünü eğitim çağındaki çocuklar oluşturduğundan bu çocukların eğitimi Türkiye açısından öncelikli bir sorun alanı olmuştur. İlk yıllarda Suriyelilerin kısa vadede geri dönecekleri varsayımı ile Milli Eğitim Bakanlığı (MEB) tarafından oluşturulan geçici eğitim merkezlerinde eğitim gören Suriyeli öğrencilere Arapça müfredat ile eğitim verilmiştir. Ancak Suriyelilerin kısa vadede beklenen dönüşlerinin gerçekleşmemesi ve geçici barınma merkezlerinin kapatılmaya başlanmasıyla beraber geçici eğitim merkezlerinde Türkçe öğrenemeyen Suriyeli çocukların topluma uyumu gecikmiştir (Emin, 2016). Bu eksikliğin giderilmesi amacıyla MEB tarafından zaman içerisinde yapılan projeler ve uygulanan çeşitli politikalar ile bu öğrenciler Türk eğitim sistemine entegre edilmeye çalışılmıştır. Türkiye'de örgün eğitim kapsamında bulunan okullarda (anaokulları, ilkokullar, ortaokullar ve liseler) eğitim almaya başlayan Suriyeli öğrenciler Türkçe'yi anlama ve konuşma sorunu ile karşı karşıya kalmışlardır (Sarıtaş, Şahin ve Çatalbaş, 2016; Levent ve Çayak, 2017; Tamer, 2017; Sahin ve Sumer, 2018; Taskin ve Erdemli, 2018). Bu sorun Pryor'e (2001) göre, mülteci çocukların eğitime yönelik fırsatlardan eşit yararlanabilmeleri önünde büyük bir engel oluşturmaktadır. Mercan Uzun ve Bütün (2016), dil problemi yaşayan yabancı uyruklu öğrencilerin öğretmenleriyle iletişime geçememelerinin yanı sıra akranları ile iletişimlerinin sınırlı olduğu, sınıfta yalnız kaldıkları ve yaşadıkları sorunlar ile tek başlarına mücadele etmek zorunda kaldıkların belirtmektedirler. Buna ek olarak, dil probleminden dolayı yabancı uyruklu öğrenciler; kendini ifade edememe, dersleri takip edememe (Takır ve Özerem, 2019), okula uyum sağlayamama, akademik başarısızlık, devlet okullarında eğitim görmeyi istememe, sık sık devamsızlık yapma ve okulu terk etme (Şahin ve Şener, 2019) gibi konularda da sorun yaşamaktadırlar.

Geçici eğitim merkezlerinde ve örgün eğitim kapsamında öğrenim gören mülteci öğrencilerin Türkçe öğrenmelerini destekleyerek Türk eğitim sistemine entegre olmalarını sağlamak amacıyla Millî Eğitim Bakanlığı ile AB Türkiye Delegasyonu arasında yapılan anlaşma ile 2016 yılında PICTES 
(Promoting Integration of Syrian Children into Turkish Education System) adlı proje hayata geçirilmiştir (Sülükçü ve Savaş, 2018). Bu projenin Suriyeli öğrencilerin Türkçe öğrenmesine katkı sağladığı ancak dil öğretim materyalleri, ders kitabı ve eğitim teknolojilerinin yetersizliği gibi nedenlerden dolayı öğrencilerin Türkçe öğrenmelerinin yavaşladığı görülmüştür (Şahin ve Şener, 2019). Diğer yandan yabancı uyruklu öğrencilerin Türkçe öğreniminde yaşadıkları diğer bir sorunun da okulda aldıkları Türkçe eğitimini günlük hayata aktarmakta ve yansıtmakta zorlanmalarıdır. Suriyeli öğrencilerin daha çok aynı dili konuştuğu öğrencilerle arkadaşlık etmesi, aile içerisinde Türkçenin kullanılmaması, ev ortamında Türkçe televizyon kanallarının takip edilmemesi, daha çok aynı dili konuşan aileler arasında sosyal ilişkilerin geliştirilmesi ve ebeveynlerin çocukların ana dillerini kullanmaları için baskı yapması gibi faktörlerin bu duruma neden olduğu söylenebilir. Bütün bunların sonucu olarak dil probleminden dolayı özellikle Türkiye'nin sınır illerinde Suriyelilerin yoğunlukta olduğu mahalleler oluşmuştur. Bu tip kültürel savunma mahallelerinin oluşması okul çağında bulunan Suriyeli çocukların Türkçeyi öğrenmeleri ve geliştirmeleri açısından dezavantaj meydana getirmektedir. Bu dezavantajların ortadan kaldırılması noktasında Türkçe öğretiminde çok çeşitli yöntem ve teknikleri kullanılmaktadır. Bu yöntem ve teknikleri öğretmen rehberliğinde öğrenci katılımıyla gerçekleştirilmektedir. Öğretmenin mülteci öğrencilerin kültürüne yabancı olması ve öğrenme stillerini tam olarak algılayamaması öğretmen-öğrenci etkileşimini olumsuz yönde etkilemektedir. Bu durum da öğrenmenin önünde engel teşkil etmektedir. Bu sorunu giderebilmek amacıyla kullanılan yöntemlerden birisi de bu çalışmanın ana konusu olan akran öğretimi yöntemidir.

Akran öğretimi, ortaklaşa ve işbirlikçi öğretim ve öğrenme stratejisini tanımlayan bir terimdir (Ünver ve Akbayrak, 2013). Topping (1996) akran öğretimini "benzer sosyal grup içinde olan, profesyonel olarak öğretmen olmayan bireylerin birbirlerine öğrenmek ve öğretmek için yardımcı olmaları" şeklinde tanımlarken; Ercan ve Yıldırım Orhan (2016) akran öğretiminin, akranların birbirleri ile olan etkileşimlerinden ve birbirlerini taklit etmelerinden ortaya çıan sosyal öğrenme olduğunu ifade etmişlerdir. Bundan dolayı akran öğretiminin, öğretmen rehberliğinde bilgi ve beceri düzeyi yüksek olan öğrencilerin öğrenmeyi henüz gerçekleştiremeyen öğrencilere yardımcı olma süreci olduğu söylenebilir. Akran öğretiminin öğrenciler arasında etkileşimi sağlama, akademik başarıyı artırma, öğrencilerde dersle- 
re karşı olumlu tutum geliştirme (Yıldırım ve Canpolat, 2019), öğrenci memnuniyetini ve motivasyonunu artırma (Field, Burke, McAllister ve Lyold, 2004) gibi çeşitli yararları bulunmaktadır. Tekin İftar (2003) akran öğretimi ile ilgili yapılan çeşitli çalışmaları inceleyerek bu yöntemin hem akademik hem de sosyal becerilerin öğretiminde kullanılabileceği ve öğrenciler (taraflar) arasında olumlu bir etkileşim geliştirebileceği sonuçlarına ulaşmıştır. Akran öğretimi; her öğrenciye kendi hızında ilerleme, süreç içerisinde anında dönüt alma, bilişsel ve duyuşsal hazır bulunuşluğu dikkate alma ve öğrenciler arasındaki kaynaşmayı sağlama özellikleri açısından önem arz etmektedir.

Türkiye'ye göç eden öğrencilerin eğitim sürecinde dil açısından okuma ve yazma becerilerinden daha çok konuşma ve anlama becerilerinde sorun yaşadığı çeşitli araştırmacılar tarafından (Biçer ve Alan, 2017; Levent ve Çayak, 2017; Tamer, 2017; Bulut, Soysal ve Gülçiçek, 2018; Güngör ve Şenel, 2018; Güven ve İşleyen, 2018; Agcadağ Çelik, 2019; Karaağaç ve Güvenç, 2019) ortaya konmuştur. Öğrencilerin okul kültürüne uyum sağlaması, akranlarıyla olumlu sosyal ilişkiler geliştirmesi ve derslerdeki akademik başarılarının artması için konuşma ve anlama becerilerinin gelişmesinin çok önemli olduğu açıktır. Bu konuda sorun yaşayan yabancı uyruklu öğrencilerin Türkçe bilen akranlarından yardım alarak iletişim sorunlarının azalacağı ve akranlarıyla iletişim kurarken daha hızlı Türkçe öğrenecekleri (Sarıtaş, Şahin ve Çatalbaş, 2016) düşünülmektedir. Araştırmadan elde edilecek sonuçların özellikle sınıfında yabancı uyruklu öğrenci bulunan öğretmenlere Türkçe öğretiminde alternatif bir yöntem olarak katkı sağlayacağı söylenebilir. İlgili literatürde bu çerçevede bir çalışmaya ulaşılamamasının bu çalısmayı özgün bir hale getirdiği söylenebilir.

$\mathrm{Bu}$ araştırmanın amacı, Türkçe konuşma ve anlama becerilerinde sorun yaşayan öğrenciler üzerinde akran öğretimi yönteminin etkisini incelenmektir. Bu amaç doğrultusunda aşağıdaki sorulara yanıt aranmıştır:

1. Akran öğretimi uygulaması öncesinde, kontrol ve deney gruplarının Türkçe konuşma ve anlama düzeyleri arasında anlamlı farklılık bulunmakta midır?

2. Deney grubunun uygulama öncesi ve uygulama sonrası Türkçe konuşma ve anlama düzeyi arasında anlamlı farklılık bulunmakta mıdir? 
3. Kontrol grubunun uygulama öncesi ve uygulama sonrası Türkçe konuşma ve anlama düzeyi arasında anlamlı farklılık bulunmakta m-dır?

4. Akran öğretimi uygulaması sonrasında, deney ve kontrol gruplarının Türkçe konuşma ve anlama düzeyleri arasında anlamlı farklılık bulunmakta mıdır?

\section{Yöntem}

\section{Araştırma Modeli}

Yabanc uyruklu (Suriyeli) öğrencilerin Türkçe öğrenimi sürecinde akran öğretiminin etkisini incelemeyi amaçlayan bu çalışma, nicel araştırma yöntemlerinden biri olan deneysel yönteme göre tasarlanmıştır. Deneysel araştırmalarda temel amaç, değişkenler arasında oluşturulan neden-sonuç ilişkisini test etmektir (Büyüköztürk vd., 2018). Bu çalışmada, yarı deneysel araştırma türlerinden biri olan ön test/son test eşitlenmemiş kontrol gruplu model kullanılmıştır. Bu model, özellikle uygulamaya katılacak olan bireyleri yansız olarak seçmenin oldukça zor olduğu eğitim araştırmalarında kullanılmaya en uygun modeldir (Baştürk, 2009). Bu modele göre, her iki gruba öncelikle ön test uygulanmaktadır. Daha sonra deney grubuna deneysel müdahalede bulunulurken, kontrol grubuna özel bir müdahalede bulunulmamaktadır. Uygulama yapıldıktan sonra ise her iki gruba da son test uygulanmaktadır (Özmen, 2016, s.57). Aşağıda bu modele ilişkin şematik gösterim verilmiştir.

\begin{tabular}{llll}
\hline Grup & Ön test & Uygulama & Son test \\
\hline Deney Grubu & $\mathrm{O}_{1,1}$ & Akran Öğretimi & $\mathrm{S}_{1,2}$ \\
\hline Kontrol Grubu & $\mathrm{O}_{2,1}$ & & $\mathrm{~S}_{2,2}$ \\
\hline
\end{tabular}

\section{Örneklem}

Araştırmanın çalışma evrenini Gaziantep'in Nizip ilçesinde bulunan bir ilkokuldaki yabancı uyruklu (Suriyeli) öğrenciler oluşturmaktadır. Araştırmanın örneklemi ise, bu ilkokulun 1. (58 öğrenci) ve 2. sınıf (34 öğrenci) düzeyinde öğrenim gören 92 yabancı uyruklu öğrenciden ( 54 kız ve 38 erkek) oluşmaktadır. Deney grubunda 50 öğrenci ( 27 kız ve 23 erkek), kontrol grubunda ise 42 öğrenci ( $27 \mathrm{kız}$ ve 15 erkek) bulunmaktadır. 


\section{Uygulama Süreci}

Araştırmaya dâhil edilecek öğrencilerin belirlenmesi amacıyla öncelikle sınıf öğretmenleri ile görüşme yapılmıştır. Görüşme kapsamında öğretmenlerden, sinfflarında bulunan yabancı uyruklu (Suriyeli) öğrenciler içerisinden Türkçe konuşma ve anlama becerisi zayıf olan öğrencilerin tespitinin yapılması istenmiştir. Öğretmenlerden alınan görüşler doğrultusunda, Türkçe konuşma ve anlama becerisinin zayıf olduğu düşünülen öğrenciler, araştırma kapsamına alınmaları amacıyla görüşme ve test sorularına tabi tutulmuştur. Bu öğrenciler ile okulda görevli olan tercüman eşliğinde birebir görüşmeler yapılmıştır. Görüşmelerde öğrencilere, adı, soyadı, babasının adı, babasının mesleği, nerede ikamet ettiği, kaçıncı sınıfa gittiği gibi soruların yanı sıra 15 görselden oluşan test de uygulanmıştır. Sorulara verilen cevaplar sonucu öğrenciler, Türkçe konuşma ve anlama düzeylerine göre araştırma kapsamına dâhil edilmiş veya edilmemiştir. Araştırma kapsamına dâhil edilen 92 öğrencinin yansız şekilde dağıtılması ile deney ve kontrol grupları oluşmuştur. Görüşmeler ve uygulanan test sonucu belirlenen öğrencilerden deney grubuna dâhil edilen 50 öğrenci sınıflarındaki Türk kökenli akranlarıyla eşleştirilmiştir. Öğrencilerin akranlarıyla eşleştirilmelerinde; sınıf öğretmeninin görüşü çerçevesinde öğrencilerin birbirleriyle anlaşabilmesi ve iletişim kurmakta zorlanmaması, eşleştirilecek Türk öğrencinin kendini açıçca ifade etme yeteneğine sahip olması ve eşleştirilen akranların ikamet adreslerinin yakın olması gibi durumlar göz önünde bulundurulmuştur.

Araştırma kapsamında Türk öğrencilerin Suriyeli akranlarına öğretmeleri amacıyla her hafta 20 kelimeden oluşan formlar hazırlanmıştır. Formlar hazırlanırken sınıf öğretmenlerinin görüşleri doğrultusunda 1. ve 2. sınıf Türkçe ders kitabında sıklıkla yer alan kelimeler göz önünde bulundurulmuştur. Aynı zamanda kelimelerin seçiminde; öğrencilerin yakın çevresinde karşılaşabilmesi, günlük yaşamda sık kullanılması ve telaffuzunun kolay olması gibi özellikler dikkate alınmıştır. İlk haftalarda verilen kelimelerin içerisine bilindiği varsayılan birkaç kelime koyulmuştur. Bu uygulamanın amacı, öğrencilerin Türkçe kelimeleri bildiğinin farkına varması ve çalışma kapsamında gerçekleştirilecek öğrenme öğretme sürecinde özgüvenin gelişmesi ve motivasyonunun güçlenmesinin sağlanmasıdır. 
Araştırma kapsamında eşleştirilen Türk öğrencilere her hafta 20 kelimeden oluşan formlar teslim edilmiştir. Formlar her öğrenciye birer adet teslim edilmiştir. Akran öğretiminin etkili bir şekilde uygulanabilmesi için deney grubunda yer alan yabancı uyruklu öğrenciler ile Türk öğrenciler sınıflarında aynı sırada oturtulmuşlardır. Süreç kapsamında öğrencilerin ders dışı saatlerde birlikte zaman geçirmesi için ortam hazırlanarak öğrenme öğretme sürecinin gerçekleştirilmesi sağlanmıştır. Yani, 5 haftalık akran öğretimi uygulaması boyunca bu öğrencilerin, sınıf ve okul içerisinde birlikte zaman geçirmesi teşvik edilmiştir. Süreç boyunca sinıf öğretmenleri öğrencilere rehberlik etmiştir. Türk öğrenciler, öğretmekte zorlandıkları kelimelerle ilgili sınıf öğretmenlerinden yardım alarak sürece devam etmişlerdir.

\section{Verilerin Toplanması}

Araştırmanın amacına uygun şekilde veriler ön test, haftalık ve son test şeklinde toplanmıştır. Öncelikle uygulama sürecinin başında belirlenen yabancı uyruklu (Suriyeli) öğrencilere ön test yapılmış ve yapılan ön teste ait veriler araştırmacılar tarafından muhafaza edilmiştir. Uygulama süreci toplam 5 hafta sürmüştür. Her haftanın sonunda, belirlenen Türk öğrencilere teslim edilen 20 kelimelik formlarda yer alan sözcüklerden yabancı uyruklu öğrenciler sınav yapılarak ilerleme durumları izlenmiştir. 5 haftalık uygulama sürecinin sonunda yapılacak son test için de değerlendirme formu hazırlanmıştır. Bu değerlendirme formu, 5 hafta içerisinde verilen formlarda yer alan kelimelerden oluşan 30 soruluk bir formdur. Aynı zamanda, hazırlanan bu formların çalışmanın amacına ve öğrencilerin gelişim düzeylerine uygunluğunu belirlemek amacıyla 3 sinıf öğretmeninin ve Türkçe eğitimi alanında çalışan 2 öğretim üyesinin görüşleri alınmıştır. Alınan görüşler doğrultusunda bu formlara son şekli verilerek akran öğretimi uygulamasında kullanılmıştır. Bu kelimelerin öğrenilme durumunu ölçmek amacryla iki yöntem uygulanmıştır.

1. Kelimeler değerlendirici tarafından söylenmiş ve sonrasında öğrencinin kelimenin karşılığı olduğunu düşündüğü görseli göstermesi/işaretlemesi istenmiştir.

2. Öğrencilerden, değerlendirici tarafından gösterilen görselin ne olduğunun söylenmesi istenmiştir. 


\section{Verilerin Analizi}

Araştırma kapsamında elde edilen veriler SPSS 22 paket programı kullanılarak analiz edilmiştir. Öncelikle deney ve kontrol gruplarına ait verilerin normal dağılım gösterip göstermediğini belirlemek amacıyla çarpıklık ve basıklık katsayıları incelenmiştir. Elde edilen değerlerin -2 ile +2 arasında (George ve Mallery, 2003) yer aldığı dikkate alınarak normal dağılım gösterdiği kabul edilmiştir. Gruplara ait verilerin normal dağılım gösterdiği belirlendikten sonra, gruplar arasında karşılaştırma yapmak amacıyla t-testi uygulanmışır. Grupların puan ortalamaları arasındaki farkın istatistiksel anlamlılık düzeyi olarak .05 değeri esas alınmıştır.

\section{Bulgular}

$\mathrm{Bu}$ araştırmada, yabancı uyruklu (Suriyeli) öğrencilerin Türkçe öğrenimi sürecinde akran öğretiminin etkisi incelenmektedir. Bu amaç doğrultusunda öncelikle deney ve kontrol gruplarının akran öğretimi uygulaması öncesinde Türkçe konuşma ve anlama düzeylerine ilişkin bulgular Tablo 1'de verilmiştir.

Tablo 1. Deney ve kontrol gruplarının ön test puanlarna ilişkin bağımsız t-testi sonucu

\begin{tabular}{lcccccc}
\hline Grup & $\mathbf{N}$ & $\mathbf{X}$ & SS & sd & t & p \\
\hline Deney & 50 & 4.94 & 3.95 & \multirow{2}{*}{13.664} & \multirow{2}{*}{-0.287} & $0.779^{*}$ \\
\hline Kontrol & 42 & 4.61 & 2.01 & & &
\end{tabular}

${ }^{*} \mathrm{p}>05$

Tablo 1'de deney ve kontrol grubunda yer alan öğrencilerin ön test puanları üzerinde yapılan bağımsız gruplar için t-testi sonucu incelendiğinde aralarında anlamlı bir fark olmadığ $[\mathrm{t}(13,664)=-0.287, \mathrm{p}>.05]$ tespit edilmiştir. Uygulanan ön test sonucuna göre deney grubu ortalama puanı $(X=4.94)$ iken kontrol grubunun ortalama puanı $(X=4.61)$ olarak ölçülmüştür. Bu bulgu ışığında, uygulama öncesinde deney ve kontrol gruplarının Türkçe konuşma ve anlama düzeylerinin benzer olduğu sonucuna varılabilir.

Araştırmaya katılan deney grubu öğrencilerinin akran öğretimi uygulaması öncesinde ve sonrasında Türkçe konuşma ve anlama düzeylerine ilişkin bulgular Tablo 2'de verilmiştir. 
Tablo 2. Deney grubu ön test ve son test puanlarna ilişkin bağımlı t-testi sonucu

\begin{tabular}{cccccccc}
\hline Grup & Ölçüm & $\mathbf{N}$ & $\mathbf{X}$ & $\mathbf{S S}$ & $\mathbf{s d}$ & $\mathbf{t}$ & $\mathbf{p}$ \\
\hline $\begin{array}{c}\text { Deney } \\
\text { Grubu }\end{array}$ & Ön test & 50 & 4.84 & 2.19 & \multirow{2}{*}{49} & \multirow{2}{*}{-10.632} & \multirow{2}{*}{$0.000^{*}$} \\
\cline { 2 - 5 } & Son test & 50 & 11.30 & 5.09 & & & \\
\hline
\end{tabular}

${ }^{*} \mathrm{p}<.05$

Tablo 2'de deney grubunda yer alan öğrencilerin ön test ile son test puanları üzerinde yapılan bağımlı gruplar için t-testi sonucu incelendiğinde anlamlı bir fark olduğu [t(49)=-10.632, $\mathrm{p}<.05]$ tespit edilmiştir. Tespit edilen anlamı farkın kaynağını belirlemek için aritmetik ortalamalara bakıldığında, son test ortalama puanının $(X=11.30)$ ön test ortalama puanına $(X=4.84)$ göre daha yüksek olduğu görülmektedir.

Araştırmaya katılan kontrol grubu öğrencilerinin akran öğretimi uygulaması öncesinde ve sonrasında Türkçe konuşma ve anlama düzeylerine ilişkin bulgular Tablo 3'te verilmiştir.

Tablo 3. Kontrol grubu ön test ve son test puanlarna ilişkin bağımlı t-testi sonucu

\begin{tabular}{cccccccc}
\hline Grup & Ölçüm & $\mathbf{N}$ & $\mathbf{X}$ & SS & sd & t & p \\
\hline $\begin{array}{c}\text { Kontrol } \\
\text { Grubu }\end{array}$ & Ön test & 42 & 4.61 & 3.95 & \multirow{2}{*}{12} & \multirow{2}{*}{-3.426} & \multirow{2}{*}{$0.005^{*}$} \\
\cline { 2 - 5 } & Son test & 42 & 5.77 & 3.96 & & & \\
\hline
\end{tabular}

${ }^{*} \mathrm{p}<.05$

Tablo 3'te kontrol grubunda yer alan öğrencilerin ön test ile son test puanları üzerinde yapılan bağımlı gruplar için t-testi sonucu incelendiğinde anlamlı bir fark olduğu [t(12)= -3.426, $\mathrm{p}<.05]$ tespit edilmiştir. Tespit edilen anlamlı farkın kaynağını belirlemek için aritmetik ortalamalara bakıldığın$\mathrm{da}$, son test ortalama puanının $(X=5.77)$ ön test ortalama puanına $(X=4.61)$ göre daha yüksek olduğu görülmektedir.

Araştırmaya katılan deney ve kontrol gruplarının akran öğretimi uygulaması sonrasında Türkçe konuşma ve anlama düzeylerine ilişkin bulgular Tablo 4'te verilmiştir.

Tablo 4. Deney ve kontrol gruplarının son test puanlarna ilişkin bağımsız t-testi sonucu

\begin{tabular}{|c|c|c|c|c|c|c|}
\hline Grup & $\mathbf{N}$ & $x$ & SS & sd & $t$ & p \\
\hline Deney & 50 & 11.30 & 5.08 & \multirow{2}{*}{61} & \multirow{2}{*}{-3.635} & \multirow{2}{*}{$0.001^{*}$} \\
\hline Kontrol & 42 & 5.77 & 3.96 & & & \\
\hline
\end{tabular}

${ }^{*} \mathrm{p}<.05$

Tablo 4'te deney ve kontrol grubunda yer alan öğrencilerin son test puanları üzerinde yapılan bağımsız gruplar için t-testi sonucu incelendiğinde deney grubu lehine anlamlı bir fark olduğu $[\mathrm{t}(61)=-3.635, \mathrm{p}<.05]$ tespit edil- 
miştir. Tespit edilen anlamlı farkın kaynağını belirlemek için aritmetik ortalamalara bakıldığında, deney grubunun son test ortalama puanının $(X=11.30)$ kontrol grubunun son test ortalama puanına $(X=5.77)$ göre daha yüksek olduğu görülmektedir.

\section{Tartışma ve Sonuç}

Yabancı uyruklu öğrencilerin yaşadıkları topluma entegrasyonlarında içinde yaşadıkları toplumun dilini kullanmalarının önemi bu çalışmada öne çıkarılmıştır. Bu entegrasyon sürecinde ise yabancı uyruklu öğrencilerin dil öğrenmesinde akran öğretimi yönteminin etkili olduğu sonucuna varılmıştir.

Araştırmanın örnekleminde yer alan deney ve kontrol grubu öğrencilerinin ön test sonuçlarından bu öğrencilerin Türkçe konuşma ve anlama düzeylerinde anlamlı bir farklılığın olmadığı belirlenmiştir. Bu sonuç, İslamoğlu ve Alnıaçık (2016) tarafından ifade edilen deney ve kontrol gruplarının deneysel işlem öncesinde homojen olmaları gerekliliğini sağlamaktadır. Deney ve kontrol gruplarının Türkçe konuşma ve anlama seviyelerinin benzer olması grupların yapılacak çalışma için uygun olduklarını göstermektedir.

Araştırma kapsamında deney grubuna uygulanan dil öğreniminde akran öğretiminin etkililiğini belirleme noktasında, deney ve kontrol grubunda yer alan öğrencilere ilişkin son test puanları karşılaştırılmış ve deney grubu lehine anlamlı bir farklılık olduğu tespit edilmiştir. Bu bulgu ışığında, akran öğretimi yönteminin dil öğretiminde etkili olduğu söylenebilir. Fuchs ve Fuchs (2005) tarafından yapılan araştırmada da mevcut araştırma bulgusunu destekler nitelikte, akran desteği alan öğrencilerin kelimeleri tanıma, akıcı okuma ve okuduklarını anlama becerilerinde kontrol grubundan daha başarılı oldukları bulgusuna ulaşılmıştır. Ünver ve Akbayrak da (2013) akran öğretimi ile öğrencilerin performansları arasında pozitif bir korelasyon olduğunu belirtmiştir. Tan (2019) tarafından yapılan araştırmada ise öğrencilerin akranlarından yeni kavramları öğrenebildiği ve bunun sonucunda akademik başarılarının arttığı tespit edilmiştir. Akran öğretimi; öğrenen akran grubunun derslerde öğrendikleri kelimeleri kullanma ve akranlarıla iletişimlerini artırmakla beraber, mutluluk ve kendini iyi hissetme duygularını geliştirme (Türkmenoğlu, 2016), olumlu sosyal etkileşimi kazandırma (Güven ve Aydın, 2007), öğrencilerin okula bağlılığını ve okul sevgisini 
artırma, öğrencilerin motivasyonlarını güçlendirme (Yeşiloğlu, Karaca ve Şimşek, 2017), öğrencilerin arkadaşları ile birlikte zaman geçirme, işbirliği fırsatı yaratma ve grup çalışmalarına teşvik etme (Ogelman ve Erten, 2013) gibi çeşitli açılardan oldukça önemlidir.

Araştırma kapsamında akran öğretiminin dil öğrenimi üzerinde olumlu etkisini gösteren diğer bir bulgu ise, deney grubu üzerinde yapılan ön test ve son test verilerine bağlı olarak elde edilmiştir. Deney grubu üzerinde yapılan analizler sonucunda, ön test ile son test ortalamaları arasında son test lehine anlamlı bir farklılık olduğu belirlenmiştir. Elde edilen bu bulgu, akran öğretimi uygulamasının yabancı uyruklu öğrencilerin Türkçe konuşma ve anlama düzeylerine pozitif etki sağladığını göstermektedir. Bu bulguya dayanarak, öğrencilerin dil gelişiminin desteklenmesi ve geliştirilmesi amacıyla akran öğretimi yönteminin etkili bir şekilde kullanılabileceği söylenebilir. Türkmenoğlu ve Baştuğ'un (2017) yaptığ1 çalışmada akran öğretimi uygulaması sonucunda öğrenen akran grubunun okuduğunu anlama düzeylerinde artış olduğu belirlenmiştir. Benzer şekilde Fuchs ve diğerleri (1997) tarafından yapılan çalışmada da akran öğretimi uygulanan ilköğretim öğrencilerinin hem okuduğunu anlama hem de akıcı okuma başarılarında önemli gelişmeler sağladığı bulunmuştur. Bahsi geçen çalışmalar ile mevcut araştırma bulgularının örtüştüğü görülmektedir.

Dil öğreniminde akran öğretiminin etkili bir yöntem olduğunu ispatlayan bir başka bulgu da kontrol grubunun ön test ve son test puanlarının karşılaştırılmasıyla elde edilmiştir. Kontrol grubu verileri üzerinde yapılan analizlerde, ön test ile son test ortalamaları arasında anlamlı bir farklılık olduğu ancak tespit edilen bu farkın deney grubunda elde edilen anlamlı farklılığa göre çok güçlü düzeyde olmadığı söylenebilir. Çünkü 5 haftalık uygulama sonucunda deney grubunun ön test ve son test puanlarmın ortalamaları arasındaki fark olumlu yönde 6,46 düzeyinde iken; akran öğretiminin uygulanmadığı kontrol grubunun ön test ve son test puanlarının ortalamaları arasindaki fark ise olumlu yönde 1,15 düzeyindedir. Kontrol grubunda yer alan öğrencilerin Türkçe konuşma ve anlama düzeylerindeki düşük seviyeli gelişme, öğrencilerin sınıf veya okul içerisinde ya da okul dışındaki etkileşimleriyle ilişkilendirilebilir. Kontrol grubunda yer alan öğrencilerin Türkçeye maruz kalmalarından dolayı dil gelişimlerinin olması beklenen bir durumdur. Ancak yapılan bu araştırma öğrencilerin dil gelişimlerinin daha hızlı olabilmesi için öğrencilerin ders ortamı dışında da dile 
maruz kalmaları amacıyla akran öğretimi yönteminin etkili bir şekilde kullanılabileceğini göstermektedir.

Bütün bu tartışmalar, akran öğretiminin dil öğrenimine pozitif etki eden bir uygulama olduğunu göstermektedir. Çalışma sonucunda deney grubunda yer alan öğrencilerin öğretmenlerinin teşviki ve yönlendirmesiyle kısa bir süre içerisinde Türkçe konuşma ve anlama düzeylerinde hızlı bir ilerleme kat ettikleri sonucuna ulaşılmıştır. Akran öğretimi uygulaması ile Türkçeyi daha iyi kullanabilir hale gelen öğrencilerde farklı etkilerin de ortaya çıkması beklenebilir. Bu öğrencilerin kendini ifade etme becerilerinin gelişmesi ile birlikte özgüvenlerinin artabileceği söylenebilir. Türkçe konuşma ve anlama düzeyleri gelişen öğrencilerin derslere aktif katılım sağlayacakları ve buna paralel olarak akademik başarılarının artacağı düşünülebilir. Diğer yandan akran öğretimi sürecinde yer alan öğrenciler arasında iletişim ve etkileşimin artması sonucunda yabancı uyruklu öğrencilerin sosyal uyum süreçlerinde hızlanma ve okula bağlılıklarında gelişme gibi sonuçların ortaya çıkması olasıdır. Bu çerçevede;

$\checkmark$ Yabancı uyruklu öğrencilerin bulunduğu çeşitli sinıf düzeylerinde dil öğrenimini kolaylaştırmak ve hızlandırmak amacıyla akran öğretimi yöntemi uygulanabilir. Sosyal ve akademik etkileri göz önüne alındığında akran öğretimi yönteminin bütün sınıflarda uygulanması önerilebilir.

$\checkmark \quad \mathrm{Bu}$ çalışma Türkiye'deki Suriyeli mülteci öğrenciler üzerinde yapılmıştır. Benzer çalışmalar farklı milletlere mensup yabancı uyruklu öğrenciler üzerinde de yapılabilir 


\title{
EXTENDED ABSTRACT
}

\section{The Effect of Peer Teaching on the Turkish Learning Process of Foreign Students: An Experimental Study}

\author{
Mevlüt Kara - Sevilay Şahin - Seyfettin Kapat \\ Gaziantep University, Ministry of National Education
}

The concept of migration dates back to ancient times and has been the case for different reasons throughout history. Apart from the requirements such as finding food and pasture in ancient times, migration has been based on the reasons such as sustaining people's lives, meeting their educational and economic needs with the industrial revolution and global wars. It is defined as the process of individuals or communities to move from one country to another, from one settlement to another, for economic, social and political reasons (Turkish Language Association [TDK], 2019). Turkey is among the mostly affected countries by the migration mobility due to adopting policies that embrace the victims of the crises in the region (Directorate General of Migration Management [GIGM], 2017).

The opposition movement, which started with the demonstrations on the 15 $5^{\text {th }}$ of March, 2011 in Syria and spread across the whole country in April 2011, turned into a civil war in a short time. Western countries did not accept the refugees who fled from their country's political impotence, living conditions, and oppressive regime due to high security policies after the September 11, 2001 (Danıs, 2004). The civilians living in Syria have been forced to migrate to neighbouring countries such as Jordan, Egypt, Lebanon and Turkey. Turkey followed an 'Open Door' policy for Syrian asylum seekers and admitted all refugees without discrimination.

The wave of migration, which started in small groups, has become a mass migration over time. Due to the increasing number of refugees, all of them could not be placed in temporary accommodation centres and distributed to various provinces of the country. In this regard, as the substantial proportion of Syrian refugees migrated to Turkey consisted of school-age children, their training has been a major issue of top priority for Turkey. Syrian students who began to be educated in the schools (kindergartens, 
elementary schools, secondary schools and high schools) within the scope of formal education in Turkey experienced the problem of understanding and speaking Turkish (Levent and Çayak, 2017; Sahin and Sumer, 2018; Sarıtaş, Şahin and Çatalbaş, 2016; Tamer, 2017; Taskin and Erdemli, 2018). One of the methods used to overcome this problem is peer teaching method, which is the main area of interest of this study.

Peer teaching is a term that refers to joint and cooperative teaching and learning strategy (Ünver and Akbayrak, 2013). While Topping (1996) defines peer teaching as "helping individuals who are in a similar social group to learn and teach each other without being professional teachers", Ercan and Yildırım Orhan (2016) indicated that peer teaching is social learning emerging from the interactions and imitation of peers with each other. Therefore, it can be claimed that peer teaching is the assistance process of the students with high level of knowledge and skills for those who are not yet able to learn under the guidance of teachers. Peer teaching has various benefits such as creating interaction among students, improving academic achievement, developing positive attitudes towards the lessons (Yildirım and Canpolat, 2019), increasing student satisfaction and motivation (Field, Burke, McAllister and Lyold, 2004). Tekin Ifftar (2003), who examined various studies on peer teaching, concluded that this method can be used in teaching both academic and social skills and can develop a positive interaction between the students (parties). Peer teaching is essential in terms of the capability of every student to progress at their own pace, to take immediate feedback during the process, to consider cognitive and affective readiness, and to ensure cohesion among students.

It has been revealed by various researchers (Agcadağ Çelik, 2019; Biçer and Alan, 2017; Bulut, Soysal and Gülçiçek, 2018; Güngör and Şenel, 2018; Güven and İşleyen, 2018; Levent and Çayak, 2017; Karaağaç and Güvenç, 2019; Tamer, 2017;) that the students who migrated to Turkey had trouble in speaking and comprehension skills rather than reading and writing in the process of language education. Considering that foreign students who have such problems try to communicate with their Turkish-speaking peers and learn Turkish faster through it (Sarıtaş, Şahin and Çatalbaş, 2016), the effect of peer teaching method on the troubling students with the skills of speaking and comprehension in Turkish was investigated in this study. It can be asserted that the prospective research results will exclusively contribute to 
the teachers who have foreign students in their classes as an alternative method in teaching Turkish. It is possible to say that the inability to reach a similar study in the relevant literature demonstrates the originality of this study.

This study, which aimed to examine the effect of peer teaching on the Turkish learning process of foreign students (Syrian), is designed according to the experimental method which is among the quantitative research methodology. Nonrandomized control group pre-test/post-test model, one of the semi-experimental research designs, was used in this study. The universe of the study consisted of the foreign students (Syrian) in primary schools in Turkey. The research sample included 92 students (54 girls and 38 boys) studying at the $1^{\text {st }}$ and $2^{\text {nd }}$ grades of a primary school with a high number of foreign students (Syrian) in Nizip district of Gaziantep province. The experimental and control groups were formed through the neutral distribution of 92 participating students. Within the scope of the research, a list consisting of 20 words were arranged for Turkish students to teach their Syrian peers on a weekly basis. Within the scope of the study, the lists of 20 words were submitted to the Turkish students every week. The wordlists were delivered to each student one by one. During the intervention procedure, the educational process was realized through an environment for the students to spend time outside class hours. The research data were collected as pre-test, on a weekly basis and post-test in accordance with the purpose of the study. The obtained data were analysed using SPSS 22 software package. Firstly, it was examined whether the data of the experimental and control groups distributed normally. After determining that the data of the two groups showed normal distribution, $\mathrm{t}$-test was used to compare the groups. The statistical significance level of .05 was adopted for the difference between the mean scores of the two groups.

The importance of using the local language for foreign students' integration into the society they live in was emphasized in this study. During this process of integration, it was revealed that peer teaching method was effective in foreign students' learning language. It was determined that there was no significant difference between the level of speaking and understanding in Turkish based on the pre-test results of the experimental and control group students. Within the scope of the study, the post-test scores of the students in the experimental and control groups were compared and a sig- 
nificant difference was found in favour of the experimental group which included peer teaching in the process of language learning. In light of this finding, it can be claimed that peer teaching method is effective in language teaching. Another finding of the study indicating the positive effect of peer teaching on language learning was based on the pre-test and post-test data of the experimental group. As a result of the analyses for the experimental group, it was established that there was a significant difference between the pre-test and post-test mean scores in favour of the latter. This finding shows that peer teaching practice has a positive effect on the foreign students' level of speaking and understanding Turkish. All these suggest that peer teaching is an implementation that contributes to language learning. As a result of the study, it was concluded that the students in the experimental group made a rapid progress for the levels of speaking and understanding in Turkish in a short period of time with the encouragement and guidance of their teachers.

\section{Kaynakça / References}

Agcadağ Çelik, İ. (2019). Sınıf öğretmenleri gözünden Suriyeli mülteci çocuklar. Uluslararast Sosyal Araștrmalar Dergisi, 12(66), 662-680.

Baştürk, R. (2009). Deneme modelleri. A. Tanrö̈ğen (Ed.), Bilimsel araştrrma yöntemleri içinde (s. 29-54). Ankara: Anı Yayıncilk.

Biçer, N. ve Alan, Y. (2017). Yabancı dil olarak Türkçe öğrenen Suriyelilerin ihtiyaçlarına yönelik bir eylem araştırması. International Online Journal of Educational Sciences, 9(3), 862-878.

Bulut, S., Soysal, Ö. K. ve Gülçiçek, D. (2018). Suriyeli öğrencilerin Türkçe öğretmeni olmak: Suriyeli öğrencilerin eğitiminde karşılaşlan sorunlar. Uluslararası Türkçe Edebiyat Kültür Eğitim (TEKE) Dergisi, 7(2), 1210-1238.

Büyüköztürk, Ş., Kilıç Çakmak, E. ve Akgün, Ö. E. Karadeniz Ş. ve Demirel, F. (2018). Bilimsel araştrrma yöntemleri. Ankara. Pegem Akademi.

Danış, A. D. (2004). Yeni göç hareketleri ve Türkiye. Birikim Dergisi, 184-185, 216-224.

Emin, M. N. (2016). Türkiye'deki Suriyeli çocuklarn eğitimi: Temel eğitim politikaları. İstanbul: SETA Yayınları.

Ercan, H. ve Ylldırmm Orhan, Ş. (2016). Bireysel çalgı ve öğretimi dersinde akran öğretimine dayalı öğrenme öğretme yaklaşım. Abant İzzet Baysal Üniversitesi Eğitim Fakültesi Dergisi, 16(İpekyolu Özel Sayıs), 2269-2281. 
Ergün, H. B. (2017). Zorunlu göç etmiş etnik gruplara mensup yetişkin bireylerde agresyon eğilimi. Yayınlanmamış yüksek lisans tezi. Haliç Üniversitesi Sosyal Bilimler Enstitüsü, İstanbul.

Field, M., Burke, J. M., McAllister, D. ve Lloyd, D. M. (2007). Peer-assisted learning: a novel approach to clinical skills learning for medical students. Medical Education, 41(4), 411-418.

Fuchs, D. ve Fuchs, L.S. (2005). Peer-assisted. learning strategies: Promoting World recognition, fluency, and reading comprehension in young children. The Journal of Special Education, 39(1), 34-44.

Fuchs, D., Fuchs, L. S., Mathes, P. G., ve Simmons, D.C. (1997). Peer-assisted learning strategies: Making classroom more responsive to diversity. American Educational Research Journal, 34(1), 174-206.

George, D. veMallery, P. (2003). SPSS for Windows step by step: A simple guide and reference (4 th Ed.). Boston: Allyn and Bacon.

Göç İdaresi Genel Müdürlüğü. (2017). 2016 Türkiye göç raporu. https://www.asylumineurope.org/sites/default/files/resources/2016_goc rapor u .pdf adresinden erişilmiştir.

Güngör, F. ve Şenel, E. A. (2018). Yabanc uyruklu ilkokul öğrencilerinin eğitimöğretiminde yaşanan sorunlara ilişkin öğretmen ve öğrenci görüşleri. Anadolu Üniversitesi Ĕ̈itim Bilimleri Enstitüsü Dergisi, 8(2), 124-173.

Güven, S. ve İşleyen, H. (2018). Sinff yönetiminde iletişim, iletişim engelleri ve Suriyeli öğrenciler. Journal of Social And Humanities Sciences Research (JSHSR), 5(23), 12931308.

Güven, Y. ve Aydın, A. (2007). Özel gereksinimli çocuklar için akran öğretimine ilişkin ilköğretim öğretmenlerinin görüşleri. Anadolu Üniversitesi Sosyal Bilimler Dergisi, 7(1), 415-432.

İslamoğlu, A. H. ve Alnuaçı, Ü. (2016). Sosyal bilimlerde araştrma yöntemleri. İstanbul: Beta Yayinları.

Karaağaç, F. C. ve Güvenç, H. (2019). Resmi ilkokullara devam eden Suriyeli mülteci öğrencilerin eğitim sorunları. OPUS Uluslararası Toplum Araştırmalan Dergisi, 11(18), 530-568.

Levent, F. ve Çayak, S. (2017). Türkiye'deki Suriyeli öğrencilerin eğitimine yönelik okul yöneticilerinin görüşleri. Hasan Ali Yücel Ĕ̈itim Fakültesi Dergisi, 14-1(27), 21-46.

Mercan Uzun, E. ve Bütün, E. (2016). Okul öncesi eğitim kurumlarındaki Suriyeli sığınmacı çocukların karşlaşııları sorunlar hakkında öğretmen görüşleri. Uluslararası Erken Çocukluk Eŏitimi Çalı̧malan Dergisi, 1(1), 72-83. 
Ogelman, H. G. ve Erten H. (2013). 5-6 yaş çocuklarının akran ilişkileri ve sosyal konumlarının okula uyum düzeyleri üzerindeki yordayıcı etkisi (Boylamsal çalışma). Selçuk Üniversitesi Sosyal Bilimler Enstitüsü Dergisi, 30, 153-163.

Özmen, H. (2016). Deneysel araştırma yöntemi. Metin, M. (Ed.), Eğitimde bilimsel araştrrma yöntemleri içinde (s. 47-76). Ankara: Pegem Akademi Yayıncllk.

Pryor, B.C. (2001) New immigrants and refugees in American schools: Multiple voices. Childhood Education, 77(5) 275-283.

Sahin, S. ve Sümer, S. (2018). The problems experienced in the integration process of Syrian students into the Turkish Education System. Universal Journal of Educational Research, 6(5), 909-918.

Sartaş, E., Şahin, Ü. ve Çatalbaş, G. (2016). İkkokullarda yabancı uyruklu öğrencilerle karşlaşlan sorunlar. Pamukkale Üniversitesi Sosyal Bilimler Enstitüsü Dergisi, 25(1), 208-229.

Somuncu, B. (2006). Türkiye'nin Avrupa Birliği'ne tam üyelik sürecinde uluslararast göç politikası. Yayınlanmamış yüksek lisans tezi. Dokuz Eylül Üniversitesi Sosyal Bilimler Enstitüsü, İzmir.

Sülükçü, Y. ve Savaş, O. (2018). PICTES Türkçe dil yeterliklerine yönelik program ve ölçek geliştirme çalıstayı raporunun değerlendirilmesi. Erciyes Journal of Education, 2(2), 59-74. doi: 10.32433/eje.440480

Şahin, F. ve Şener, Ö. (2019). Geçici koruma altındaki Suriyeli öğrencilerin eğitim süreçlerindeki dil ve iletişim sorunlarr: İstanbul Fatih örneği. Avrasya Sosyal ve Ekonomi Arasttrmaları Dergisi, 6(9), 66-85.

Takır, A. ve Özerem, A. (2019). Göçle gelen yabanc uyruklu öğrencilerin okul ortammda karşılaştkları sorunlar. Folklor/edebiyat Dergisi, 25(97-1), 659-678.

Tamer, M. G. (2017). Geçici koruma kapsamındaki Suriyeli çocukların Trabzon devlet okullarındaki durumu. Göç Dergisi (GD), 4(2), 119-152.

Tan, E. (2019). Ortaöğretim 7.smuf ışık konularnnda akran öğretiminin uygulanmasl.Yayınlanmamış doktora tezi. Atatürk Üniversitesi Eğitim Bilimleri Enstitüsü, Erzurum.

Taskin, P. ve Erdemli, O. (2018). Education for Syrian refugees: Problems faced by teachers in Turkey. Eurasian Journal of Educational Research, 18(75), 155-178.

Tekin Iftar, E. (2003). Effectiveness of peer delivered simultaneous prompting on teaching community signs to students with developmental disabilities. Education and Training in Developmental Disabilities, 38(1), 77-94.

Topping, K. J. (1996). The effectiveness of peer tutoring in further and higher education: A typology and review of the literature. Higher Education, 32(3), 321-345.

Türk Dil Kurumu. (2019). Güncel Türkçe Sözlïk. 
Türkmenoğlu, M. (2016). İkokulda akran öğretimi arachlğ̆yla okuma güçlü̆g̈unün giderilmesi.Yayınlanmamış yüksek lisans tezi. Niğde Üniversitesi Eğitim Bilimleri Enstitüsü, Niğde.

Türkmenoğlu, M. ve Baştuğ, M. (2017). İkokulda akran öğretimi aracillğyla okuma güçlüğünün giderilmesi. Eğitimde Nitel Araştırmalar Dergisi, 5(3), 36-66.

Ünver, V. ve Akbayrak, N. (2013). Hemşirelik eğitiminde akran eğitim modeli. Dokuz Eylül Üniversitesi Hemşirelik Fakültesi Elektronik Dergisi, 6(4), 214-217.

Yeşiloğlu, Ö., Karaca, S. ve Şimşek, Ö. (2017). Akran öğretimi yönteminin ortaokul öğrencilerinin fen ve teknoloji dersindeki başarnya etkisi. Akademik Sosyal Araştırmalar Dergisi, 5(41), 309-320.

Yıldırım, T. ve Canpolat, N. (2019). Lise düzeyinde çözeltiler konusunun öğretiminde akran öğretimi yönteminin etkililiğinin incelenmesi. Ĕ̆itim ve Bilim, 44(199), 127-147.

\section{Kaynakça Bilgisi / Citation Information}

Kara, M., Şahin, S. ve Kapat, S. (2020). Yabancı uyruklu öğrencilerin Türkçe öğrenme sürecinde akran öğretiminin etkisi: Deneysel bir çalışma. OPUS-Uluslararası Toplum Araştırmaları Dergisi, 16(Eğitim ve Toplum Özel Sayıs1), 5974-5994. DOI: 10.26466/opus.730411 